\title{
Vergi Uyumunu Belirleyen Faktörlere Genel Bir Bakış
}

\author{
Volkan YURDADOĞ ${ }^{*}$ Ramazan GÖKBUNAR** Barış TUNÇAY***
}

\begin{abstract}
$\ddot{O} Z$
Vergi toplama hakkl, devletlerin bağımsızlık göstergelerinden birisidir. Dünya tarihine bakıldı̆̆ında vatandaşlarından vergi toplamayan hiçbir devlet olmadığ görülmektedir. Gönüllü vergi uyumu ve vergi kaçakçıllı̆̆ gibi konular, verginin kendisi kadar eski olup, verginin varllğından bu yana önemli araştırma alanları olmuştur. Günümüzde de vergi uyumu literatüründe kişiler "niçin vergi öderler ya da niçin vergi ödemek istemezler?" sorularına cevap aranmaktadır.

Ekonomik, sosyo-psikolojik, politik, etik, yönetimsel ve hukuki boyutları olan vergi uуumunu belirleyen faktörler çok çeşitlidir. Tüm ülkelerde giderek artan şekilde sürdürülebilir bir kamu finansmanı oluşturulması ihtiyacı nedeniyle vergi uyumu üzerinde yoğun bir şekilde araştırmalar yapılmaktadır. Çalışmada amaç, vergi uyumunu belirleyen faktörleri genel olarak incelemektir.
\end{abstract}

Anahtar Kelimeler: Vergi Uyumu, Vergi Kaçakçıllğ̆, Vergi Denetimi.

JEL Sinıflandirmasi: H2O, H26.

\section{An Overview of The Factors Determining Tax Compliance}

\begin{abstract}
The right to collect taxes is one of the independence indicators of the states. Given the history of the world, there seems to be no state that did not collect taxes from citizens. Topics such as voluntary tax compliance and tax evasion are dated back to the taxation itself. They have constituted an important research area since the early days of tax collection practices. Today, there ise a search for answers in the relevant literature to the following questions; "Why do people pay taxes?" or "Why are people reluctant to pay taxes?".

There is a variety of factors affecting tax compliance that incorporates a range of dimensions including interalia economic, socio-psychological, political, ethical, administrative and legal. Due to the growing need for the establishment of a sustainable public finance system across the world, there is an intensive research agenda on tax compliance. Overall, the purpose of this study is to discuss the factors that affect and determine tax compliance.
\end{abstract}

Key Words: Tax Compliance, Tax Evasion, Tax Audit.

JEL Classification: H2O, H26.

\section{GíRiş}

Vergi ödemek temel bir vatandaşl1k görevidir. Vergi uyumu konusu, verginin kendisi kadar eski bir konu olup, vergi yükünün geniş bir kitle üzerinde olması nedeniyle güncelliğini korumaktadır. Geçmişten günümüze bireyler, "Verginin ne olduğu ve neden vergi ödedikleri" gibi soruların cevabını arayarak verginin meşruiyetini/hukuksallığını ve ödedikleri vergilerin hesabını hep sorgulamışlardır.

\footnotetext{
*Yrd. Doç. Dr., Çukurova Üniversitesi, İ.İ.B.F., Maliye Bölümü, vyurdadog@ @u.edu.tr

** Prof. Dr., Manisa Celal Bayar Üniversitesi, İ.İ.B.F., Maliye Bölümü, ramazan.gokbunar@cbu.edu.tr

*** Araş. Gör., Manisa Celal Bayar Üniversitesi, İ.İ.B.F., Maliye Bölümü, baris.tuncay@cbu.edu.tr
} 
Vergi uyumunun politik, ekonomik, yasal, psikolojik ve sosyolojik boyutları söz konusudur. Özellikle vergi uyumu ile ilişkili ekonomik unsurların bazı yönleri halihazırda bilinmektedir (Bayer ve Cowell, 2015: 38). Son yıllarda vergi uyumu literatüründe "İnsanlar neden vergi kaçırır?" sorusu yerine artık "İnsanlar neden vergi öder?" sorusuna cevap aranmakta olup, bireyleri vergisel yükümlülükleri yerine getirmede daha uyumlu davranmaya, doğru bilgi vermeye nelerin öncülük ettiği merak edilmektedir (Kitapc1, 2014: 25; Gökbunar ve Gökbunar, 2007: 91). Özellikle vergi uyumsuzluğunun açıklanması ve nihai olarak vergiye uyumsuzluk düzeyinin azaltılması oldukça önemlidir (Andreoni v.d., 1998: 818). Devletin vergileme konusundaki temel görevi, vatandaşları vergi yükümlülüklerini yerine getirme ve vergi kurallarına uygun davranma hususunda motive etmektir. Örneğin (Kirchler v.d., 2008: 210-211): Vatandaşlar, (i) vergiye uyum sağlamadıklarında bunun kendileri için maliyetinin yüksek olacağını hesaplayabilir veya (ii) toplumun bir üyesi oldukları için kendilerini vergiye uyum sağlamada yükümlü hissedebilirler.

Günümüzde vatandaşların devletin sunduğu kamusal mal ve hizmetlerin finansmanına yaptıkları cebri katkılar olarak kabul edilen (Canbay, 2009: 4) vergiler, toplumsal bir hizmetin karş1lığı olsa da bireylerin kullanılabilir gelir, servet ve harcamalarında azalmalara yol açmaktadır. Dolayısıyla vergiler çoğunlukla bireyler tarafından bir yük olarak hissedildiğinden, bu yükten kurtulmak için vergiden kaçınma, vergi kaçakçıllğı gibi çeşitli yasal ve yasal olmayan yollara başvurulabilmektedir (Karaaslan ve Sandalc1, 2015: 38). Mükelleflerin vergi kanunlarındaki boşlukları kullanarak vergiden kaçınmaları durumu, vergi uyumsuzluğu olarak kabul edilmemekle birlikte tartışmalı bir konudur (Benk ve Budak, 2015: 167).

$\mathrm{Bu}$ çalışmada, maliye literatüründe vergi uyumunu belirleyen faktörler konusunda yapılan çalışmalar genel olarak incelenecektir.

\section{GENEL OLARAK VERGİ UYUMU}

Vergi mükelleflerinin, vergisel ödevlerini tam olarak yerine getirdiklerinde vergiye uyum sağladıkları düşünülür. Günümüzde bireylerin vergiye uyumu/vergi kaçırmamaları iyi vatandaşlık göstergesi olarak kabul edilmektedir.

Vergi uyumu, radyoda doğru frekansı ayarlamak gibidir. Radyonun ayar düğmesi rastgele çevrilirse, kendi kendine mükemmel bir şekilde çalışıyor olmasına rağmen, bulunan kanal hakkında hiçbir fikir sahibi olunmaz ya da bulunan kanaldaki dilin anlaşılacağının hiçbir garantisi yoktur. Fakat radyo doğru bir kanala ayarlanırsa, o kanalın yayınının dinlenmesi umulur ve daha da önemlisi, radyolarını aynı kanala ayarlayanların aynı şeyi dinleyecekleri öngörülür (Eiser, 1986: 342).

Genel olarak üç grup vergi mükellefi vardır (Torgler, 2007: 103): (i) hiç vergi kaçırmayan mükellefler, (ii) şimdi ya da ileride vergi kaçırmayı deneyecek ve bu çabayı sürdürecek olan mükellefler, (iii) vergi kaçırmayı alışkanlık haline getirenler. Bir bireyin vergi uyumu konusundaki istekli olma hali zamanla değişebilir. 
Vergi uyumu literatüründe benzer mali sisteme sahip olan pek çok ülkede farklı vergi uyumu deneyimleri olduğuna dair kanıt bulunmaktadır. $\mathrm{Bu}$ konuyla ilgili temel çıkarımlar şunlardır (Torgler, 2002: 664): (i) bireyler, etik olmayan bir şekilde vergi kaçırma eğilimine uyma görüntüsü verebilmekte, (ii) vergi mükelleflerine etik değerler kazandırıldığında vergiye uyum artabilmekte, (iii) vergi kaçıranlarla arkadaş olan bireylerin kendileri de vergi kaçırmaya yatkın hale gelebilmekte, (iv) sosyal bağ /aidiyet duygusu daha güçlü toplumlarda vergi uyumu daha yüksek olabilmektedir. Vergiye uyumu yükseltmek için denetimler ve cezalar gibi geleneksel zorlayıcı politikaların uygulanmasında hükümetler için sınırlamalar bulunmakta, daha çok gönüllü uyum politikaları başarılı olabilmektedir.

Vergi uyumu konusunun genel çerçevesi "karşıt (zit) vergileme iklimi" ve "sinerjik vergileme iklimi” arasında sürekli değişmektedir. Karşıt iklimde vergi mükellefi ve vergi otoriteleri birbirlerine karş1; sinerjik iklimde ise birlikte/işbirliği halinde çalışılar. Bu vergileme iklimleri (Kirchler vd., 2008: 211):

(i) Zıt vergileme iklimi "polis ve hırsız" davranışı olarak nitelendirilebilir. Vergi otoriteleri vergi mükelleflerini "hırsız" gibi algılarlar; vergi mükellefleri de baskıc1 vergi otoritelerini polis gibi hissederler ve onlardan gizlenmenin doğru olduğunu düşünürler. Böyle bir ortam, vergiye gönüllü uyum düzeyini azaltmakta ve mükelleflerin vergiye uyumsuzluğun kendileri açısından oluşturacağı faydalar ve maliyetler arasında bir karşılaştırma yapmasını rasyonel kılmaktadır.

(ii) Sinerjik vergileme iklimi, vergi otoritesinin (Devlet) toplum için kamu hizmeti sunduğu ve vergi mükelleflerinin de devletin hizmet sunduğu aynı toplumun bir parçası olduğu düşüncesi ile nitelendirilebilir. Bu çerçevede vergiye gönüllü uyum daha fazla gerçekleşmekte olup, vergi idareleri, vergi mükelleflerinin davranışlarını desteklemeyi ve daha şeffaf uygulamaları amaçlamaktadır.

James Alm ve Michael Mckee'nin yaptığ 1 deneysel çalışmalara göre, vergi uyumuna ilişkin ortaya çıkan bazı sonuçlar şunlardır (Alm ve Mckee, 1998: 270):

- S1k yapılan vergi denetimi, yakalanma olasılığının az ve doğrusal olmayan etkisine rağmen daha yüksek vergiye uyumu özendirir.

- Düzenli vergi denetimleri, vergi uyumunu artırmada rastlantısal denetimlerden daha etkilidir.

- Vergi ceza oranlarındaki artış marjinal olarak vergiye uyumu arttırır.

- Marjinal vergi oranlarındaki bir artış vergiye uyumu azaltır.

- Vergiye uyum kararı iş gücü arzı kararını özendirir.

- Reel gelirde artış, vergiye uyumu arttırır.

- Ödenen vergi karşı1lı̆̆nda iyi bir kamu hizmeti alındığı düşüncesi mükellefleri daha fazla vergi ödemeye yönlendirir.

- Vergiye uyum ödülle teşvik edilebilir. 
- Vergiye uyum, bireylerin adaletsizliğin kaynağına bakmadan (Örneğin; vergi ya da harcama yönlü) diğerlerine göre kendilerine adaletsiz davranıldığını hissettikleri durumlarda azalır.

- Bireyler, kendi seçtikleri ve destekledikleri kamu programıyla karşılaştıklarında daha fazla vergiye uyum gösterirler.

- Belirli bir dönemde uygulanan vergi affi sonrasında vergi suçlarına gerekli yaptırım uygulanmazsa, bir sonraki vergi affinda vergi uyum düzeyi daha düşük olur.

- Bireylerin vergi uyum düzeyini etkileyen en önemli unsur olan sosyal kurallar, birey davranışları ve hükümet politikalarından etkilenir.

Vergi uyumunu şekillendiren vergi ahlakının kurumsal, sosyal ve psikolojik belirteçleri konusundaki temel çalışmalar aşağıdaki tabloda yer almaktadir.

Tablo 1: Vergi Uyumu Literatürünü Gözden Geçirme

\begin{tabular}{|c|c|}
\hline Schanz (1890) & $\begin{array}{l}\text { Politik sistemin, mükellefler ve vergi yetkilileri arasında yakın bir } \\
\text { mübadele iliskisini kolaylastırmasının değerlendirilmesi. }\end{array}$ \\
\hline Schmölders (1951-1952) & $\begin{array}{l}\text { Mükelleflerin kamu politikalarından memnuniyet derecesinin } \\
\text { değerlendirilmesi. }\end{array}$ \\
\hline $\begin{array}{l}\text { Schwartz ve Orleans } \\
\text { (1967) }\end{array}$ & Bireylerin sosyo-ekonomik durumlarının değerlendirilmesi. \\
\hline ve Lundstedt & $\begin{array}{l}\text { (a) Mükelleflerin vergi ödeme karşılığı olarak gördükleri devletten } \\
\text { elde ettikleri kamusal malların niceliği/niteliği konularının } \\
\text { değerlendirilmesi. } \\
\text { (b)Mükelleflerin, diğer mükelleflerin vergiden kaçındığını } \\
\text { hissetmesinin değerlendirilmesi. }\end{array}$ \\
\hline Lewis & $\begin{array}{l}\text { Vergilerin miktarı ile elde edilen kamu mallarının değeri arasındaki } \\
\text { boşluğun değerlendirilmesi. }\end{array}$ \\
\hline Spic & $\begin{array}{l}\text { Vatandaşların adil olmayan vergi sistemi uygulaması hakkındaki } \\
\text { düşüncelerinin değerlendirilmesi. }\end{array}$ \\
\hline $\begin{array}{l}\text { Benjamini ve Maital } \\
\text { (1985), } \\
\text { Gordon (1989) }\end{array}$ & $\begin{array}{l}\text { Vatandaşların hissettikleri vergi yükü ve vergi kaçakçıllğının } \\
\text { üzerlerinde oluşturduğu psikolojik etkinin değerlendirilmesi. }\end{array}$ \\
\hline d. (1987) & $\begin{array}{l}\text { Vergi mükelleflerinin vergi sisteminden olduğu kadar vergi } \\
\text { yönetiminden de memnuniyetlerinin değerlendirilmesi. }\end{array}$ \\
\hline $\mathrm{Co}$ & \\
\hline Smitl & $\begin{array}{l}\text { Kamu yetkililerine olan güvenin mükellefleri gönüllü vergi } \\
\text { ödemeye yönlendirmesi konusunun değerlendirilmesi. }\end{array}$ \\
\hline Sheffrin ve Triest (1992) & $\begin{array}{llcc}\text { Vergi sistemine karşı negatif bir tutum içinde olma ve diğer } & \text { ver } \\
\text { mükelleflerin dürüst } & \text { davranmadığını } & \text { hissetmenin } & \begin{array}{c}\text { bireylerin } \\
\text { vergiden kaçınma } \\
\text { değerlendirilmesi. }\end{array} \\
\text { delasılığını } & \text { arttırması } & \text { konusunun } \\
\end{array}$ \\
\hline $\begin{array}{l}(1992) \\
\text { n (1993) }\end{array}$ & $\begin{array}{l}\text { Sağlanan kamu hizmetlerinin maliyetinin doğru hesaplandığı ve } \\
\text { dağıtıldığına olan düşüncenin mükelleflerde daha fazla oranda vergi } \\
\text { ödemek zorunda oldukları düşüncesine yol açmasını } \\
\text { değerlendirilmesi. }\end{array}$ \\
\hline & yıbı konularının değerlendirilmesi. \\
\hline Falkinger (1 & sistemindeki adaletin değerlendirilmesi. \\
\hline
\end{tabular}




\begin{tabular}{|c|c|}
\hline Pommerehne v.d. (1997) & $\begin{array}{l}\text { Vergi mükelleflerinin doğrudan demokrasi sistemiyle karar verici } \\
\text { olarak katılımının değerlendirilmesi. }\end{array}$ \\
\hline Tyler $(1997,2001)$ & $\begin{array}{l}\text { Adalet (prosedürel) anlayışının yetkililerin meşruluğunu } \\
\text { sağlamadaki öneminin değerlendirilmesi. }\end{array}$ \\
\hline Scholz ve Lubell (1998) & $\begin{array}{l}\text { Dürüst vatandaşların devlete güvenleri ve vergi sistemindeki adaleti } \\
\text { hissetmelerinin değerlendirilmesi. }\end{array}$ \\
\hline Feld ve Frey (2002a) & $\begin{array}{l}\text { Vergi yetkilileri ve vergi mükellefleri arasındaki ilişki ile kurumsal } \\
\text { farklılıkların değerlendirilmesi. }\end{array}$ \\
\hline Frey $(2002 b)$ & $\begin{array}{l}\text { Vergi yetkililerince mükelleflerin vergi ödemeye zorlanmış bireyler } \\
\text { olarak görülüp/görülmemesinin değerlendirilmesi. }\end{array}$ \\
\hline Tyler & $\begin{array}{l}\text { Meşruluğun algılanması: (a) vergi sisteminde adaletin hissedilmesi, } \\
\text { (b) vergi otoritesine güven (c) kurumun kendilerini temsil } \\
\text { edebilirliliğinin değerlendirilmesi. }\end{array}$ \\
\hline $\begin{array}{l}\text { Orvi } \\
(200\end{array}$ & Vatandaşlık görevi ve kanuna itaatın değerlendirilmesi. \\
\hline Torg & esi. \\
\hline Torg & Politik katılım hakları üzerindeki farklılıkların değerlendirilmesi. \\
\hline Wenzel (2005) & 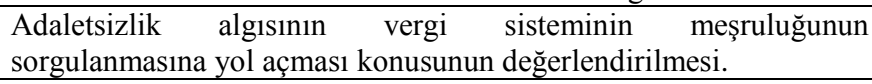 \\
\hline $\begin{array}{l}\text { Braithwaite ve Ahmed } \\
\text { (2005) }\end{array}$ & $\begin{array}{l}\begin{array}{l}\text { Popüler olmayan politikaların vergi ahlakını aşındırması, ve vergi } \\
\text { sisteminin etkinliğini tehlikeye atması konularının } \\
\text { değerlendirilmesi. }\end{array} \\
\end{array}$ \\
\hline Torg & $\begin{array}{l}\text { Ödenen vergi ve gerçekleştirilen kamu hizmetleri arasındaki } \\
\text { ilişkinin değerlendirilmesi. }\end{array}$ \\
\hline Schnellenbach (2006) & $\begin{array}{l}\text { Kamu politikalarının meşruluğunun } \\
\text { değerlendirilmesi. }\end{array}$ \\
\hline (2006) & $\begin{array}{l}\text { Vergi yükünün adaletsiz } \\
\text { mükelleflerde vergi kaçırmanın } \\
\text { açmasının değerlendirilmesi. }\end{array}$ \\
\hline Torgler (2007) & $\begin{array}{l}\text { (a) Ahlaki kurallar ve düşünceler, (b) adalet, (c) vergi mükellefleri } \\
\text { ve hükümet arasındaki ilişkinin niteliğginin değerlendirilmesi. }\end{array}$ \\
\hline Fortin v.d. (2007) & $\begin{array}{l}\begin{array}{l}\text { Hissedilen adaletsizliğin } \\
\text { değerlendirilmesi. }\end{array} \\
\end{array}$ \\
\hline Torgles & $\begin{array}{l}\begin{array}{l}\text { Yerel özerklik ve vergi ahlakı arasındaki pozitif ilişkinin } \\
\text { değerlendirilmesi. }\end{array} \\
\end{array}$ \\
\hline
\end{tabular}

Kaynak: Roberto Dell' Anno. (2009). Tax Evasion, tax morale and policy maker's effectiveness. The Journal of Socio- Economics. 38. s. 990.

\section{VERGİ UYUMUNU BELİRLEYEN FAKTÖRLER}

\section{A. Vergi Uyumu ve Vergi Bilinci}

Normatif kamu maliyesi yaklaşımına göre "devlet"in sosyal refahı veya kamu yararını maksimize etmeye çalıştığı varsayıldığından, aynı zamanda bir seçmen olan vergi mükellefinin, kamu kesimini algılaması ve siyasal otoriteden beklentisi göz ardı edilmektedir (Pınar, 2000: 98). Bu kapsamda, vergi ödemeye gönüllü olduğu, vergi sisteminin meşruluğunu kavradığı düşüncesiyle vatandaşların büyük bir kısmının kamu politikalarında hedeflenen amaçlara güvendiklerinde, vergi kaçırma veya vergiden kaçınma olasılıklarını düşünmeksizin vergi yükümlülüklerini yerine getirdikleri düşünülmektedir. 
Devletin vergi kanunlarını saydam, uygulanabilir ve mükellef odaklı şekilde düzenlenmesi vergi bilincinin artmasına fayda sağlayabilmektedir (Çetin Gerger, 2011: 61).

\section{B. Vergi Uyumu ve Denetim}

Vergi uyumu araştırmalarında denetim olasılıklarının önemi üzerine yapılan çalışmalarda zayıf etkiler bulunmuştur. Örneğin, vergi mükelleflerinin gelirlerini yakından incelemeye alarak onları korkutmak düşük ve orta gelirli vergi mükelleflerinde vergiye uyumu azaltabilir (Kirchler, v.d., 2008: 215).

Genellikle vergi denetimi ve ceza oranı gibi konular verginin dürüst olarak ödenmesine yol açmasına rağmen, vergi uyumunun temel nedeni, ya yetkililer tarafından zorlama ya da gönüllü davranış şeklinde ortaya çıkmaktadır (Kirchler ve Wahl, 2010: 333).

Yapılan deneysel araştırmalarda, vergi denetimlerinin geri dönüşünün ve sonuçlarının kısa sürede ortaya çıktığı (Kogler v.d., 2016: 81), daha fazla vergi denetiminin daha fazla vergi uyumuna yol açtı̆̆ 1 ve vergi uyumunun, gelirin artan, vergi oranlarının ise azalan bir fonksiyonu olduğu sonucuna varılmıştır (Torgler, 2002: 662).

\section{Vergi Uyumu ve Para Cezaları}

Vergi uyumu birçok değişkenden etkilenen karmaşık bir karar olup, bu konuda vergi uyumsuzluğu tehdidinin tespiti ve cezalandırılması açık bir etkendir (Cummings v.d., 2009: 456). Para cezalarıyla vergiye uyum arasındaki ilişki tutarsız sonuçlar vermektedir. Bazı çalışmalara göre, para cezalarının yüksek olduğu durumlar, denetim olasılıklarından daha fazla vergiye uyumla ilgili iken diğer çalışmalarda aksine para cezaları ile vergiye uyum arasında ilişki kurulamazken, denetim ihtimalleri ve vergiye uyum arasında ilişki kurulmaktadır (Kirchler v.d., 2008: 215).

Vergi denetiminde yakalanma ihtimallerini dikkate alarak vergiye tabi işlemlerini beyan etmemeleri halinde mükelleflerin ödeyecekleri vergi cezası, vergiye tabi işlemlerini beyan etmeleri halinde ödeyecekleri vergi miktarından daha düşük olması durumunda, vergi kaçırma eğiliminde olabileceklerdir. Ayrıca mükelleflerin denetim geçirme ve ceza görme ihtimali de yüksek ise vergi kaçakçılığı düzeyi düşecektir (Batırel, 1996: 53).

\section{Vergi Uyumu ve Vergi Oranı}

Rasyonel uyum kararlarıyla ilgili ekonomik modeller, marjinal vergi oranının uyum üzerindeki etkisi veya artan vergi oranlarını", uyumu artırma

\footnotetext{
*Klasik Ekonomik Teori’ye göre, vergi oranlarındaki artışın kişinin kaçırdığı vergiyi azaltacağı öngörüsü teorik olarak iki nedenle açıklanabilir (Saruç ve Sağbaş, 2004: 65): (i) Cezaların mükellefler tarafından beyan edilmeyen matrah üzerinden değil de çoğu ülkede olduğu gibi kaçırılan vergi miktarı üzerinden alındığı varsayımıyla, vergi oranlarındaki artış cezalarda da bir artış etkisi gösterecek ve mükellef öncekine göre daha az vergi kaçıracaktır. (ii) Ampirik çalışmalarla genel olarak insan davranışlarını doğru açıkladığı gözlenen Azalan Mutlak Risk Sevmeme (Decreasing Absolute Risk Aversion-DARA) varsayımına göre, kişiler gelirleri arttıkça eskisine oranla daha çok risk almakta, öte yandan gelirleri azaldıkça risk sevmemeleri artarak daha az risk almaktadirlar.
} 
beklentisi üzerinde belirsizlikler söz konusu olsa da çoğu ampirik araştırma, yüksek vergi oranlarının uyumu azalttığı şeklindedir (Kirchler v.d, 2008: 215).

Vergi oranının etkisi devlete olan güvene bağlıdır. Güven düşük olduğunda yüksek vergi oranı, vergi mükellefleri için adaletsiz bir uygulama olarak görülebilir. Güven yüksek olduğunda aynı seviyedeki vergi oranı topluma bir katk1 olarak değerlendirilebilir (Kirchler v.d, 2008: 216).

Vergi uyumu, hedeflenen vergi hasılatının gerçekleşmesi için önemli bir unsurdur. Daha yüksek vergi uyumu vergi hasılatını arttıracaktır (Savitri ve Musfialdy, 2016: 68) .

\section{E. Vergi Uyumu ve Vergi Bilgisi}

Vergi bilgisi vergiye uyumla doğrudan ilgilidir. Vergilerin kullanımında öznel vergi bilgisi ve kullanımı güvenle doğrudan ilgiliyken, eksik veya yanlış anlama doğrudan güvensizlikle ilgilidir. Vergiler hakkındaki bilgi düzeyinin yüksekliğinin vergiye uyumunu artırdığı, aksine daha az bilgi düzeyinin ise uyumsuzluğa neden olduğu ileri sürülmektedir. Artan eğitim-öğretim ve vergi mükellefi hizmetleri, otoriteye güveni artırmakta ve gönüllü vergi uyumuna yardımc1 olmaktadır. Kısaca, vergi uygulamaları hakkındaki bilgi seviyesi otoritenin gücüne katk1 yapmaktadır (Kirchler v.d., 2008: 216-217).

Vergi otoriteleri, bireylere veya kurumlara vergi borçlarının tamamını ödeyip ödemediklerini kolay bir şekilde soramaz; hiçbir işletme de normal olarak böyle bir suç unsurunu kendiliğinden rapor etmez. Vergi afları istisnai bir durum olarak işletmelere sorunlu mali durumlarını bildirmeleri için bir teşvik oluşturur ve sundukları bilgiler ayrıca değerlendirilir (Mikesell ve Birskyte, 2007: 1050).

\section{F. Vergi Uyumu ve Karar Verme Süreçlerine Katılım}

Doğrudan demokrasi, vergiye uyum üzerinde olumlu etki yapmaktadır. Bu durumda, vatandaşlar bütçeleme sürecinde daha fazla yer alabilmekte ve vergi sistemleri ile ilgili daha fazla bilgi almak isteyebilmektedirler. Bilgili vatandaşlar, kamu harcamasının haklı görüldüğü zamanlarda vergi artışlarını gönüllü olarak benimsemektedirler (Kirchler v.d., 2008: 216-217).

Politik karar alma sürecinde vatandaşların özellikle harcama konusu ve mali sorunlara katılımı, bireysel vergi ödemelerini artırmaktadır. Örneğin; İsviçre'de yüksek demokratik hakların varlığıyla birlikte vergi gelirlerinin de arttı̆̆ belirlenmiştir (Halla ve Schneider, 2008: 8).

\section{G. Vergi Uyumu ve Vergiye Karşı Davranışlar}

Vergi kaçakçılığına karşı vergi mükellefinin pozitif davranışları mükellefin negatif davranışlarına göre daha az uyumlu davranmasına neden olur. Vergi kaçırmaya yönelik davranışların olumlu görüldüğüne de rastlanılabilmektedir. İş adamlarının vergiye karşı davranışlarını araştıran bir ankette cevap verenlerin yarısı iş adamlarının hile ile vergi kaçırmalarını onaylarken sadece üçte biri onları vergi kaçakçısı ve hırsız olarak nitelendirmiştir (Bknz.; Kirchler v.d., 2008: 216-217; Schmölders, 1960-64).

\section{H. Vergi Uyumu ve Normlar}

Davranışların yanında kişisel, sosyal ve ulusal normlar da vergiye uyumu belirleyen önemli belirleyicilerdir. Davranışsal amaçlar kişisel normlarla 
belirlenir. Davranışsal standartlar olan normların üç farklı şekli söz konusudur. Bunlar (Kirchler v.d., 2008: 217-218):

(i). Bireysel normlar ve ahlaki konular, Makyavelizm, egoizm, normlara bağımlılık ve değerlerle ilgilidir. Bireysel normlar ile değerler ve vergi etiği birbirleriyle örtüşmekte olup, vergi etiğiyle ilgili ahlaki durumların geliştirilmesi gönüllü uyumu artırır.

(ii). Vergi yükümlüleri, vergiye uymamamanın yaygın olduğuna ve bunun örnek aldıkları grup içinde kabul edilebilir bir davranış olduğuna inanmaları durumunda kendileri de vergiye uymayacaklardır. Dolayısıyla, sosyal normlar ve vergiye uyum arasındaki ilişki karmaşıktır.

(iii). Birçok çalışmada, yönetime olan güvenin söz konusu olduğu ve ulusal normlar oluşturulduğu durumda, gönüllü vergi uyumunun artacağ 1 vurgulanmaktadir.

\section{Vergi Uyumu ve Adalet Algisı}

Adaletle ilgili araştırmalar, vergiye uyum üzerindeki adalet ile düşünceler için sürekli ve tutarlı bir kanıt sağlamasa da algılanan adalet, vergiye gönüllü uyumu artırır. Mevcut yapı içerisinde algılanan adalet güvenle bağlantılıdır. Çünkü adil vergi uygulamaları, güvenin inşasına ve sürdürülmesine yardım eder. Cezalandırıcı adalet güç boyutuyla da bağlantılıdır. Cezalandırıcı adalet anlayışı, yanlış yapanları bulmaya ve onları para cezasına çarptırmaya bağlıdır. Sonuçta aşırı güç gereksiz olarak algılanır ve bu durum güven duygusunu düşürebilir (Kirchler v.d., 2008: 219).

Daha fazla bireyin mali kuralların geliştirilmesi sürecine dahil olması, yüksek adalet algısını ortaya çıkarmaktadır. Yüksek adalet algısı, yetkili makamlara olan güveni de arttırarak daha yüksek bir seviyede vergi uyumunu ortaya çıkarmaktadır (Casal v.d., 2016: 142).

\section{İ. Vergi Uyumu ve Vergi Ahlakı}

Vergi ahlakı, mükelleflerin içsel ve dişsal etkenlere bağlı olarak iç dünyalarında oluşturdukları, yakalanma riski ve yasal cezalara bağlı olmayan, onların vergiye ilişkin tutum ve davranışlarına yön veren inanç ve değerler bütünüdür (Çoban ve Deyneli, 2013: 111).

Çoğu insan vergisini öder, vergi uyumu nihai aşamada gözlenen bir eylemdir. Uyum veya uyumsuzluk sadece firsat, vergi oranları ve yakalanma olasılığının değil, aynı zamanda bir bireyin uyma ve kaçırmaya istekliliğinin bir fonksiyonudur. Vergi ahlakı kuvvetli olduğunda, vergi uyumu nispeten yüksektir (Torgler, 2002: 658).

\section{J. Vergi Uyumu ve Kamu Harcamalarının Kullanımı}

Kamu harcamalarının etkin ve verimli kullanıldığı algısı mükelleflerin vergi uyumunu artırır.

Vergilerin, kamu hizmeti yerine borç finansmanında kullanılması (Çelikkaya ve Gürbüz, 2006: 130) mükelleflerin, kamu harcamalarından sağladıkları faydanın düşük olduğunu düşünmeleri sonucunda vergiye gönüllü uyumu olumsuz yönde etkilemektedir. 


\section{SONUÇ}

Mükellefler vergi uyumu konusunda çeşitli faktörlerden etkilenmektedir. Mükelleflerin özellikle vergi bilincine sahip olmaları, vergiye gönüllü olarak uyum sağlamaları açısından olumlu bir etki sağlarken, vergi denetimi ve para cezaları konusunda yapılan çalışmalarda vergi mükelleflerinin davranışları bazı farklılıklar gösterse de genel olarak uyum konusunda mükellefler vergi ödeme/ödememe konusunda nihai olarak kendileri açısından en çok fayda sağlayacakları durumu tercih etmektedirler. Vergisini sürekli olarak ödeyen vergi mükellefleri söz konusuyken, tam tersi vergi ödemekten kaçınan ya da riski tercih ederek vergi kaçıran mükellefler de ortaya çıkabilmektedir. Ayrıca vatandaşların önemli bir düzeyde vergi ahlakına sahip olmaları ve vergi toplanırken adaletli olunduğu konusundaki genel düşünce vergiye uyum sağlama konusunda uyumu artıcı bir etki gösterirken yine vatandaşların zaman içerisindeki birikimler sonucu sahip oldukları vergi kültürlerinin de yüksek düzeyde olması vergiye karşı tutum ve davranışlarını olumlu olarak etkilediği görülmektedir.

\section{KAYNAKÇA}

Alm, J. \& Jackson, B.R. \& McKee, M. (1992). Estimating The Determinants of Taxpayer Compliance with Experimental Data. National Tax Journal, 45, 107-114, https://www.ntanet.org/NTJ/45/1/ntj-v45n01p107-14-estimating-determinants-taxpayercompliance.pdf.

Alm, J.\& Mckee M. (1998). Extending the Lessons of Laboratory Experiments on Tax Compliance to Managerial and Decision Economics. Managerial and Decision Economics, 19(4-5), 259-275. doi: 10.1002/ (SICI) 10991468 (199806/08) 19:4/53.0. CO; 2-2.

Andreoni, J. \& Erard B. \& Feinstein J. (1998). Tax Compliance. Journal of Economic Literature, 36 (2), 818-860, http://econweb.ucsd.edu / jandreon/ Publications/ jel1998.pdf.

Barth, E. \& Cappelen, A.W. \& Ognedal, T. (2006). Fair Tax Evasion. Memorandumn. Department of Economics. Oslo University.

Batırel, Ö. F. (1996). Vergi Kaçakçılı̆̆ı ve Vergiye Gönüllü Uyum. Vergi Dünyası, 175, 52-55.

Bayer, R. \& Cowell F. (2015). Tax Compliance by Firms and Audit Policy. Research in Economics, 70, 38-52.

Benk, T. \& Budak T. (2015). Vergi Uyumunda Paradigma Dönüşümü: Neo-Klasik Perspektiften Bütüncül Yaklaşıma Geçiş. Prof. Dr. Metin Taş’a Armağan: Gazi Kitabevi, 165-184.

Benjamini, Y. \& Maital, S. (1985). Optimal Tax Evasion and Optimal Tax Evasion Policy. In: Gartner, W., Wenig, A. (Eds.). The Economics of the Shadow Economy: Springer Verlag, Berlin, 245-264.

Braithwaite, V. \&, Ahmed, E. (2005). A Threat To Tax Morale: The Case of Australian Higher Education Policy. Journal of Economic Psychology, 26 (4), 523-540.

Bordignon, M. (1993). A Fairness Approach To Income Tax Evasion. Journal of Public Economics, $52,345-362$.

Canbay, T. (2009). Dünya Vergileme Anlayışındaki Değişim (Antikçağdan Günümüze). Bursa: Dora.

Casal S. \& Kogler C. \& Mittone L. \& Kirchler E. (2016). Tax Compliance Depends on Voice of Taxpayers. Journal of Economic Psychology, 56, 141-150.

Cowell, F.A. (1992). Tax Evasion And Inequity. Journal of Economic Psychology, 13 (4), 521-543.

Cummings, R. G. \& Vazquez M. J. \& McKee M. \& Torgler B. (2009). Tax Morale Affects Tax Compliance: Evidence From Surveys and an Artefactual Field Experiment. Journal of Economic Behavior \& Organization, 70, 447-457, doi:10.1016/j.jebo.2008.02.010.

Çelikkaya, A. \& Gürbüz H. (2006). Mükelleflerin Vergiye Gönüllü Uyumunu Etkileyen Faktörlerin Analizi: Bir Alan Çalışması. İktisat İşletme Finans İnceleme-Araştırma, 21 (247), 122139. 
Çetin Gerger, G. (2011). Mükellef Hakları ve Vergiye Gönüllü Uyum. İstanbul: Legal, doi : 10.3848/iif.2006.247.0084.

Çoban, H. \& Deyneli F. (2013). Vergi Ahlak1 ve Sosyal Sermaye. Finans-Politik \& Ekonomik Yorumlar, 50(584), 109-118.

Dell'Anno, R. (2009). Tax Evasion, Tax Morale and Policy Maker's Effectiveness. The Journal of Socio- Economics, 38, 988-997, doi:10.1016/j.socec.2009.06.005.

Eiser, J. R.., (1986). Social Psychology: Attidues, Cognition and Behavior. Cambridge: Cambridge University Press.

Elffers, H. \& Weigel, R.H. \&, Hessing, D.J. (1987). The Consequences of Different Strategies For Measuring Tax Evasion Behavior. Journal of Economic Psychology, 8, 311-337.

Erard, B. \& Feinstein, J.S. (1994). The Role of Moral Sentiment And Audit Perceptions in Tax Compliance. Public Finance/Finance Publiques, 49, 70-89.

Falkinger, J. (1995). Tax Evasion, Consumption of Public Goods and Fairness. Journal of Economic Psychology, 16 (1), 63-72.

Feld, L.P. \&, Frey, B.S. (2002a). Trust Breeds Trust: How Taxpayers Are Treated. Economics of Governance, 3, 87-99.

Feld, L.P. \&, Frey, B.S. (2002b). The Tax Authority and The Taxpayer. An Exploratory Analysis. In: Paper Presented at the 2002 Annual Meeting of the European Public Choice Society, Belgirate, Italy.

Fortin, B. \& Lacroix, G. \& Villeval, M. (2007). Tax Evasion ad Social Interactions. Journal of Public Economics, 91 (11-12), 2089-2112.

Gordon, J.P.F. (1989). Individual Morality and Reputation Costs As Deterrents To Tax Evasion. European Economic Review, 33 (4), 797-805.

Gökbunar, R. \& Gökbunar, A. (2007). Mükellef Davranışları, Vergi Etiği ve Vergi Uyumu. Vergi Dünyası, 26 (311), 91-100.

Halla M. \& Schneider F. (2008). Taxes and Benefits: Two Options to Cheat on the State. IZA Discussion Paper No: 3536, https://www.deutsche-digitale-bibliothek.de/ binary/IZEDBPXFCSYCMI5HKK7SJ3ASMZO5J4SN/full/1.pdf.

Karaaslan, A. \& Sandalcı U. (2015). Vergi Ahlakını Belirleyen Faktörlerin Analizine Yönelik Bir Uygulama. Finans Politik \& Ekonomik Yorumlar, 52(607), 37-54.

Kirchler E. \& Hoelzl E. \& Wahl I. (2008). Enforced Versus Voluntary Tax Compliance: The "Slippery Slope" Framework. Journal of Economic Psychology, 29, 210-225, doi: 10.1016/j.joep.2007.05.004.

Kirchler E. \& Wahl I. (2010). Tax Compliance Inventory TAX-I: Designing An Inventory For Surveys of Tax Compliance. Journal of Economic Psycholog, 31, 331-346, doi:10.1016/j.joep.2010.01.002.

Kitapc1, İ. (2014). Vergi Etiği-Vergi Psikolojisi. Ankara: Seçkin.

Kogler C. \& Mittone L. \&, Kirchler E. (2016). Delayed Feedback on Tax Audits Affects Compliance and Fairness Perceptions. Journal of Economic Behavior\&Organization, 124, 81-87.

Lewis, A. (1979). An Empirical Assessment of Tax Mentality. Public Finance/Finances Publiques, 34 (2), 245-257.

Mikesell, J. L. \& Birskyte L. (2007). The Tax Compliance Puzzle: Evidence from Theory and Practice. International Journal of Public Administration, 30, 1045-1081, doi: 10.1080/01900690701221423.

Orviska, M. \&, Hudson, J. (2002). Tax Evasion, Civic Duty and The Law Abiding Citizen. European Journal of Political Economy, 19, 83-102.

Pınar, A. (2000). Vergilemenin Siyasal İktisadı: Literatüre Bir Bakış. Ankara Üniversitesi SBF Dergisi, 55(2), 97-111.

Pommerehne, W.W. \& Hart, A. \& Feld, L.P. (1997). Steuerhinterziehung Und ihre Kontrolle in Unterschiedlichen Politischen Systemen. Homo oeconomicus, 14, 469-487.

Saruç, N. T. \& Sağbaş İ. (2004). Mükelleflerin Vergi Eşitliğini Algılaması Vergi Kaçırma Eğilimi İlişkisi. Finans-Politik \& Ekonomik Yorumlar, 41(482), 64-74. 
Savitri, E. \& Musfialdy. (2016). The Effect of Taxpayer Awareness, Tax Socialization, Tax Penalties, Compliance Cost at Taxpayer Compliance with Service Quality as Mediating Variable. Procedia-Social and Behavioral Sciences, 219, 682-687.

Schanz, G. Von. (1890). Die Steuern der Schweiz in ihrer Entwicklung seit Beginn des 19. Jahrhunderts. I-V. Stuttgart.

Scholz, J.T. \& Lubell, M. (1998). Trust and Taxpaying: Testing The Heuristic Approach To Collective Action. American Journal of Political Science, 42, 398-417.

Schmölders, G. (1951-1952). Finanzpsychologie. FinanzArchiv, 13, 1-36.

Schmölders, G. (1960). Das Irrationale in der o" ffentlichen Finanzwirtschaft. Frankfurt am Main: Suhrkamp.

Schmölders, G. (1964). Finanzwissenschaft und Finanzpolitik. Tübingen: J. c. B. Mohr (Paul Siebeck).

Schnellenbach, J. ( 2006). Tax Morale and The Taming Of Leviathan. Constitutional Political Economy, 17 (2), 117-132.

Schwartz, R.D. \&, Orleans, S. (1967). On Legal Sanctions. University of Chicago Law Review, 34, $282-300$.

Sheffrin, S.M. \&, Triest, R.K.. (1992). Can brute deterrence backfire? Perceptions and attitudes. In: Slemrod, J. (Ed.). Why People Pay Taxes. University of Michigan Press, Ann Arbor. 193208.

Smith, K.W. (1992). Reciprocity and Fairness: Positive Incentives For Tax Compliance. In: Slemrod, J. (Ed.), Why People Pay Taxes. University of Michigan Press, Ann Arbor. 223250.

Spicer, M.W. \& Lundstedt, S.B. (1976). Understanding Tax Evasion. Public Financ, 31, 295-305.

Spicer, M.W. \& Becker, L.A. (1980). Fiscal Inequity and Tax Evasion: An Experimental Approach. National Tax Journal, 33, 171-175.

Torgler, B. (2002). Speaking to Theorists and Searching for Facts: Tax Morale and Tax Compliance in Experiments. Journal of Economic Survey, 16 (5), 657-684.

Torgler, B. (2003a). Tax Morale, Rule-Governed Behaviour And Trust. Constitutional Political Economy, 14 (2), 119-140.

Torgler, B. (2003b). Tax Morale and Institutions. Center for Research in Economics. Management and the Arts (CREMA). Working Paper. n. 2003-09, Switzerland.

Torgler, B. (2005). Tax Morale in Latin America. Public Choice, 122 (1-2), 133-157.

Torgler, B. (2007). Tax Compliance and Tax Morale (A Theoretical and Empirical Analysis): Edward Elgar Publishing Limited.

Torgler, B. \& Schneider, F. \& Schaltegger, C.A.. (2008). Local Autonomy, Tax Morale and the Shadow Economy. Center for Research in Economics, Management and the Arts (CREMA). Working Paper n. 24. Switzerland.

Tyler, T.R. (1997). The Psychology of Legitimacy: A Relational Perspective On Voluntary Deference To Authorities. Personality and Social Psychology Review, 1 (4), 323-345.

Tyler, T.R. (2001). Trust and Law-Abidingness: A Proactive Model of Social Regulation. Boston University Law Review, 81 (2), 361-406.

Tyler, T.R. \& Huo, Y.J., (2002). Trust in the Law: Encouraging Public Cooperation with the Police and Court. Russell Sage Foundation New York.

Wenzel, M. (2005). The Multiplicity of Taxpayer Identities and Their Implications For Tax Ethics. Working Paper. 73. Centre For Tax System Integrity Research School of Social Sciences. Australian National University.

\section{SUMMARY}

Undoubtedly, tax is the main source of income for the state. It is very important for the state to voluntarily adapt the taxation, which is the most important source of income. In this study, studies on tax compliance have been examined and tried to reveal the factors determining the willingness of individuals to pay taxes. 
Paying taxes is a civic duty. The issue of tax compliance is as old as the tax. From past to present individuals, have always questioned the legitimacy / legality of taxation and searching for answers to questions such as "what is the tax and what taxes are paid?".

Topics such as voluntary tax compliance and tax evasion are dated back to the taxation itself. They have constituted an important research area since the early days of tax collection practices. Taxpayers are considered to be in compliance when they fully fulfill their tax duties. Nowadays, individuals tax compliance / tax evasion is regarded as a sign of good citizenship.

As long as taxpayers are convinced that taxation policies are legitimate, intact and efficient, it is assumed that they are willing to comply in the collection process and unwilling to avoid the taxes.

There are various factors that affect taxpayer's willingness to comply to the taxation policies. Awareness of the effects of taxation is considered a positive factor in terms of tax compliance. On the other hand taxpayers prefer to act rationally when it comes to declare their tax positions, specifically speaking; when the possible gains penalty of cheating the system worth the reward, they prefer to do so regardless of their awareness level.

While personal factors such as level of moral integrity and belief of value return from the system may affect this process positively, it is assumed that these cases will be outliers and won't have a statistically significant proportion within the population to influence the macroeconomic behavior. 